6

\title{
The Effect of Waste Incineration Taxation on Industrial Plastic Waste Generation: A Panel Analysis
}

\author{
Loïc De Weerdt ${ }^{1 *}$, Toshiaki Sasao ${ }^{2}$, Tine Compernolle ${ }^{1}$, Steven Van Passel ${ }^{1}$, Simon De Jaeger ${ }^{3}$ \\ ${ }^{1}$ University of Antwerp, Prinsstraat 13, 2000 Antwerpen - Belgium \\ Department of Engineering Management and Department of Economics \\ loic.deweerdt@uantwerpen.be, tine.compernolle@uantwerpen.be, steven.vanpassel@uantwerpen.be
}

${ }^{2}$ Iwate University, 18-34, 3-Chome Ueda, Morioka, 020-8550- Japan

Faculty of Humanities and Social Sciences

tsasao@iwate-u.ac.jp

11

(1)

\footnotetext{
${ }^{3}$ KU Leuven, Warmoesberg 26, 1000 Brussel
}

Research Centre for Economics and Corporate Sustainability

simon.dejaeger@kuleuven.be

15

(1)

8

9

0

1

3

4

5

\footnotetext{
${ }^{*}$ Corresponding author
} 


\section{Keywords}

industrial waste management, waste incineration taxation, waste incineration, plastic waste generation, industrial plastic waste, dynamic panel analysis

Abstract

Waste treatment taxation is a popular policy instrument in many European countries and regions. Its impact on household waste has extensively been researched. However, only little research exists which looks into the impact of waste treatment taxation on industrial waste generation. Nevertheless, industrial waste constitutes more than ninety percent of waste generated in the European Union. This study assesses the impact of an incineration tax on the generation of industrial plastic waste in Flanders, Belgium. We conduct different types of econometrical panel analyses and provide statistical evidence that firms show lagged behavior, which means that the previous year's waste generation partly determines the current year's. The dynamic panel estimations show robust results, indicating that incineration taxes exert significant negative effects on the generation of industrial plastic waste. This result offers no argument to iteratively raise incineration taxes. We conclude that incineration taxation is meaningful if tax rates are set according to the prevailing market conditions, i.e. taking into account the marginal costs of alternatives for incineration. In the short run, the effectiveness of taxation will quickly diminish due to the rapidly rising marginal costs of waste reduction. In the long run, extra recycling capacity is needed to recycle the minimized waste fraction. The role of taxation in the long run is to maintain an equilibrium in which recycling is preferred by the market.

\section{Introduction}

Making the transition towards a Circular Economy ${ }^{1}(\mathrm{CE})$ has been set as a target by many countries and supranational unions. Leading countries and supranational unions are: China with a CE legislation (Brooks, et al., 2018), Japan with well-developed waste management practices (Sasao, 2014) and the European Union (EU). The EU is actively urging Member States (MS) to make the transition towards a $\mathrm{CE}$ via action plans and reports, the most important ones being the $7^{\text {th }}$ Environment Action Programme ${ }^{2}$ (EAP) (EC, 2013), and the action plan for a $\mathrm{CE}^{3}$ (EC, 2015; EC, 2018).

Waste management is a recurring topic in government publications on a circular economy. In the EU, both the $7^{\text {th }}$ EAP and the action plan for a CE strongly focus on waste management as well as waste minimization. Waste minimization has great potential to enable a transition towards a CE as it constitutes one of the pillars - reduce - of the 3R principle (Kirchherr, et al., 2017). Next to waste minimization, valorization of remaining waste streams should be maximized. Today, the potential of too many waste streams - reuse and recycle -, is not fully exploited (Relis, 2017). Exploiting these streams not only increases competitiveness (Porter \& Linde, 1995, Hart, 1997), it also closes material cycles, and hence enables circularity. In order to make the transition towards a CE, all three levels should be taken into account. Nevertheless, the primary focus remains to reduce waste streams while reusing and recycling is the secondary focus (Allwood, 2014). This paper aims to contribute to the former, i.e. waste minimization.

\footnotetext{
${ }^{1}$ A holistic economic system taking into account environmental, economic, and social sustainability, inspired by the reduce, reuse, and recycle (3R) principle (Kirchherr et al., 2017).

${ }^{2}$ The first EU initiatives in pursuance of the transition towards a CE were taken during the Barroso II Commission by Commissioner J. Potočnik (Potočnik, 2014). Although these initiatives were revoked by Junker's 2014 Commission (Confino, 2015), the $7^{\text {th }}$ EAP (EC, 2013) was published in 2013 and refers to a CE.

${ }^{3}$ The Junker Commission replaced the earlier initiatives by the action plan for a CE $(E C, 2015)$. This action plan is the result of a collaboration between former First Vice President of the Commission F. Timmermans, former Vice President of the Commission J. Katainen and former Commissioner for Environment, K. Vella.
} 
A popular policy tool for reducing waste generation is, among others, waste treatment taxation. From all over the world, many studies exist on waste treatment taxation, mostly, but not all, focusing on household waste (Sahlin, et al., 2007; Fullerton \& Kinnaman, 1996; Sasao, 2014). An interesting study on household waste management in Flanders, a region of the federal State of Belgium, is De Jaeger \& Eyckmans (2015). They find that weight-based pricing of municipal solid waste has a significant initial impact on the generation after its introduction. To the best of our knowledge, no study has been performed on industrial waste treatment taxation in Flanders. In general, there exists a scarcity of these kind of studies performed for industrial waste. The reason being the lack of data necessary to assess possible taxation effects. The asymmetry between the limited studies on industrial waste and the, in relative terms, dominant amount of industrial waste generation is somewhat paradoxical. According to the European Commission, about six tons of waste are generated per person per year in Europe; household waste only accounts for half a ton, industrial waste accounts for five and a half tons (EC, 2018). In relative terms, this means that approximately 92 percent of waste streams has an industrial origin and only approximately 8 percent is household waste. Therefore, studying the effect of waste treatment taxation on industrial waste generation is relevant and can enable major forward steps in both waste minimization and policy design.

In this research we will study the effect of an incineration tax on industrial plastic waste generation in Flanders. Plastics are a fiercely discussed waste streams (Hopewell, et al., 2009). Major improvements are possible, both on the level of 'reduce' and the level of 'reuse and recycle' (OECD, 2018). As a consequence, the European Commission published a plastics strategy in 2018 (EC, 2018a) and is currently working on a ban for certain single-used plastics (EC, 2018b). Guided by the EU legislation, but also driven by their own vision, the Flemish Government has been implementing waste management policies throughout the past decades. One of the structural long-term policies, which was implemented as early as 1990, is a taxation on landfilling and incineration of both household and industrial waste streams. This tax mainly has a regulatory function, promoting sustainable waste treatment, which is achieved through differentiation of tariffs (OVAM, s.a.).

As mentioned earlier, few studies exist looking at industrial waste treatment taxation. One of the scarce studies on industrial waste and taxation is performed by Sasao (2014), focusing on Japan. The research offers an overview of dynamic panel methods to measure the effectiveness of waste taxes. The study analyzes the effect of industrial waste treatment taxation on quantities of landfilled industrial waste in Japan. Sasao (2014) found that industrial waste treatment taxes only have minimal significant effects on waste disposal. Other studies, such as the study of Martin \& Scott (2003) found that a landfill tax in the UK failed to change SMEs' as well as household waste generation. Similar results are found in Bartelings et al. (2005) and Mazzanti, et al. (2012). We can say that the literature on industrial waste taxation remains inconclusive, although recent and thorough research by Sasao (2014) finds small - inelastic significant negative effects on waste generation.

The remainder of the paper is organized as follows: section 2 will look into the model and data. Section 3 elucidates on the methods, followed by the estimations in section 4. Finally, section 5 concludes on the research findings.

\section{Model and data}

For this study, we use a panel dataset called 'The Integral Environmental Annual Report'. These data are collected by the Public Flemish Waste Agency (OVAM), founded in 1981 by the Flemish Government and tasked to take care of waste management in Flanders. The data collection on waste and pollutants constitutes one of the tasks of the MS of the EU in the context of the Aarhus Convention ${ }^{4}$. Flanders exceeds the minimum criteria and keeps decent statistics. Every year or other year (depending on the type of firm) some firms (a fraction is semi-random, another fraction is not random) have to declare which

\footnotetext{
${ }^{4}$ Convention on Access to Information, Public Participation in Decision-making and Access to Justice in Environmental Matters.
} 
waste and/or pollutants they generated and/or emitted during the past year. This report is mandatory for the selected firms; lacking to report is fined. The generated waste follows multiple treatment steps, firms have to report on the first type of treatment used for the generated waste. Because the final treatment step is unknown, the data on the treatment method is of poor quality and will not be used in this study.

In this paper we instead focus on waste generation. In order to fully understand the potential relation between waste generation and waste treatment taxation, we first discuss a conceptual framework. Firms choose their optimal waste generation. This optimum is driven by (i) particularities of their production or service, determining the cost of waste reduction, (ii) by the cost of waste treatment. The modus operandi for waste generating firms in Flanders, is to contract with a waste treatment firm. Waste treatment firms are firms who collect and treat the generated waste. We assume that waste generating firms do not treat their own waste, and that the supply of waste is homogenous in terms of quality. The aim of this conceptual framework is to understand the demand for such waste treatment firms, and to understand the decision on the treatment method, made by the waste treatment firm. Treatment methods for industrial plastic waste are limited, mostly for two reasons: (i) regulations, such as prohibition to landfill, and (ii) technical and capacity constraints. In Northwestern Europe, the lion's share of treatment methods at the waste treatment firm's discretion are incineration or recycling.

Waste treatment firms compete on a price level. Waste generating firms prefer the cheapest alternative for treatment, and hence contract with the cheapest waste treatment firm. We argue that waste treatment alternatives are incineration and recycling, we regard these alternatives as substitutes among which firms can choose. Most industrial plastic waste will be incinerated, due to low incineration prices; only a small fraction will be recycled. An alternative besides waste treatment is of course reducing waste generation, and avoid the treatment price.

Under the assumption of a perfect competitive market, characterized by rising marginal costs for incineration and recycling, the waste treatment market will experience an equilibrium at which marginal costs are equal. Waste treatment firms will charge the marginal cost of the treatment to the waste generating firms, denoted by $M C_{\text {treatment }}$. Marginal costs of different waste treatment options will be equal.

$$
M C_{\text {incineration }}=M C_{\text {recycling }}=M C_{\text {treatment }}
$$

Expression (1), in which $M C_{\text {incineration }}$ and $M C_{\text {recycling }}$ respectively represent the marginal cost of incineration and recycling, indicates the existing equilibrium on the waste treatment market. Waste generating firms will minimize expenses by reducing their waste generation, as long as the marginal cost of reducing a unit of waste is smaller than the price of treating that unit. Also the marginal cost of waste reduction is assumed to be rising. When the marginal cost of reducing, $M C_{\text {reducing }}$, is higher than the treatment price, a firm will stop reducing its waste generation, this equilibrium is represented in expression (2).

$$
M C_{\text {reducing }}=M C_{\text {treatment }}
$$

Substituting expression (2) into expression (1):

$$
M C_{\text {incineration }}=M C_{\text {recycling }}=M C_{\text {reducing }}
$$

The equilibrium, represented by expression (3), is characterized by a constant distribution of waste between incineration and recycling, respectively $\left(q_{\text {incinerated }}\right)$ and $\left(q_{\text {recycled }}\right)$. The fraction of waste recycled will be lower compared to the fraction of waste incinerated. One of the reasons for this lower recycling capacity with respect to the incineration capacity is that marginal costs of recycling follow a steeper curve compared to the incineration's one. Technical challenges of recycling, among others, are a 
cause for this difference. In case we do not make the assumption of steep rising marginal costs of recycling, the dynamics remain the same. Capacity for recycling industrial plastic waste is fixed in the short run. This fixed capacity for recycling is smaller compared to the capacity for incineration. This assumption of a fixed and smaller capacity holds according to literature and empirical findings (Qu et al., 2019; Brooks et al., 2018). An important empirical finding is that the price of recycled plastics is lower than the price of virgin plastics in specific applications only, e.g. low quality plastics (Gillabel, et al., 2016). Therefore, the recycling capacity is low and is likely to remains low in the future. To increase the capacity installed, pertinent government action is required to offer incentives such that the use of recycled plastics is preferred over virgin plastics, also in higher quality applications.

After taxing incineration, the marginal cost of incineration will rise accordingly. Given the fixed recycling capacity, the market will deviate from expression (3). Marginal costs of recycling will become lower compared to the incineration's one. A new, short run, equilibrium will follow expression (4).

$$
M C_{\text {incineration }}=M C_{\text {reducing }}
$$

A change of the incineration taxes will lead to a higher treatment price, waste generating firms will review their waste generation and adapt their waste reduction accordingly.

For this study we focus on the firms who have to report on a yearly basis and are not random. These firms are registered in the 'Pollutant Release and Transfer Register' (PRTR). They were registered in the PRTR after reaching a threshold value of waste generation. As a consequence, it's obligatory for them to annually report the type and quantity of waste and/or pollutants generated/emitted as well as the first type of waste treatment. Of course, firms can unregister themselves by reducing waste generation to a level below the PRTR threshold ${ }^{5}$. Within this PRTR subset, we focus on the firms who generate 'plastic waste' a fraction which is not categorized in more detail.

As a consequence of the adopted approach, we have an unbalanced panel dataset ranging between 2005 and 2016 (12 years) with 1.154 observations, composed by 252 PRTR registered firms. The dataset is not a random sample. Therefore, one should be careful extrapolating results. The analysis consists of two parts: a first part analyzes the unbalanced panel, a second part analyzes a balanced panel. Analyzing a balanced panel allows to control for a possible selection bias.

The dataset, a micro panel - a large number of firms $(\mathrm{N})$ and a limited time frame $(\mathrm{T})$ - will be valorized with panel techniques ${ }^{6}$. Using panel data allows the exploitation of more variation in the data to estimate coefficients. Moreover, individual heterogeneity can be distinguished from microeconomic dynamics. Therefore, estimations will be more accurate compared to non-panel estimations. We estimate the following model (5):

\section{Growth waste $e_{t}$}

$$
\begin{aligned}
& \left.=\alpha+\beta_{1}\left(\text { Growth waste }_{t-1}\right)+\beta_{2} \text { (Growth tax } \text { Gro }_{t}\right)+\beta_{3} \text { (Growth treatment price } \text { Gr }_{t} \\
& \left.\left.+\beta_{4}(\text { Growth PPI })+\beta_{5} \text { (Growth GDP prim } \& \text { sec }_{t}\right)+\beta_{6} \text { (Growth GDP ter } \text { Gro }_{t}\right) \\
& +\varepsilon_{i t}
\end{aligned}
$$

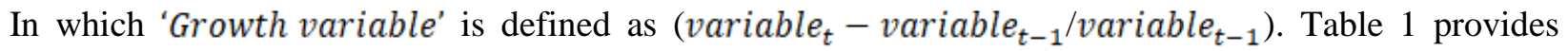
information on the variables we estimate for the unbalanced, as well as balanced panel dataset. For the sake of readability, the table reports the summary statistics before the transformation '( variable $_{t}-$ variable $_{t-1}$ variable $\left._{t-1}\right)$ ' is performed. The figures represent the yearly average ranging from 2005/2010 to 2016 for individual firms. We chose to report on the unit, mean, standard deviation

\footnotetext{
${ }^{5}$ Drastically changing waste generation as a firm is very costly. Therefore we are confident that the threshold to be registered as PRTR does not create a bias within the PRTR pool of firms.

${ }^{6}$ LSDVC, GMM, LSDV, DOLS, elaborated on is part 4.
} 
(SD), kurtosis and skewness value. The kurtosis value measures the heaviness of the tails of the distribution. A high value corresponds with a heavy-tailed distribution, a normal distribution has a kurtosis value of 3 . The skewness value measures the asymmetry of the distribution. A negative skewness corresponds with a left-tailed distribution and vice versa.

194 Table 1: Summary statistics for the unbalanced panel dataset (2005-2016), as well as for the balanced 195 panel dataset (2010-2016).

\begin{tabular}{llllll}
\hline Variable & unit & Mean & SD & Kurtosis & Skewness \\
\hline Unbalanced 2005-2016 & & & & & \\
Waste & ton & 50.18 & 212.92 & 209.00 & 12.63 \\
Incineration tax & euro/ton & 7.57 & 1.20 & 1.99 & 0.90 \\
Cost to incinerate waste & euro/ton & 85.62 & 20.34 & 2.04 & 0.01 \\
Producer Price Index (PPI) & index & 102.73 & 3.82 & 1.73 & -0.52 \\
GDP primary \& secondary sector & euro per capita & 9629.54 & 435.08 & 2.71 & 0.97 \\
GDP tertiary sector & euro per capita & 16759.12 & 478.31 & 3.11 & -0.53 \\
\hline Balanced 2010-2016 & & & & & \\
Waste & ton & 75.65 & 236.27 & 68.64 & 7.12 \\
Incineration tax & euro/ton & 7.59 & 1.51 & 1.90 & 0.95 \\
Cost to incinerate waste & euro/ton & 73.39 & 11.47 & 2.96 & -1.08 \\
Producer Price Index (PPI) & index & 104.89 & 2.19 & 3.69 & -1.45 \\
GDP primary \& secondary sector & euro per capita & 9396.61 & 182.36 & 2.11 & 0.59 \\
GDP tertiary sector & euro per capita & 16999.31 & 286.93 & 1.68 & 0.63 \\
\hline
\end{tabular}

All prices are in real terms with 2004 as base year

The coefficient 'waste' is the reported tons of waste in 'The Integral Environmental Annual Report' questionnaire. In case this waste is incinerated, it will be taxed according to that particular year's incineration tax. The Flemish region predominantly regulates its industrial waste management by taxing ${ }^{7}$ certain types of waste treatment, e.g. landfilling and waste incineration, information as well as taxation levels can be found on the website of the OVAM (https://ovam.be/). The Flemish framework for waste treatment taxation was first introduced in 1990. To prevent tax avoidance via exports of waste, the same taxes have been applicable for exported waste since 1997. In 2007 the legislation was simplified and made clearer by reducing 40 possible fees to 16 possible fees. Landfilling became more expensive than incineration, redirecting waste flows away from landfills. Moreover, landfilling is very restricted in Flanders; many waste streams are not allowed to be landfilled. Currently, only three types of landfills exist for very specific types of waste, plastics can only be landfilled if they are contaminated with these other types of waste. Therefore, we only focus on incineration taxation. This tax rate is equal for every firm $^{8}{ }^{9}$. The underlying motivation of taxation is to incentivize sustainable waste treatment more intensively. However, for industrial plastic waste, it is expected that taxes only influence the generation and not so much the treatment in the short term cf. supra. Figure 1 shows the incineration tax per ton, applicable to industrial high caloric value waste, such as plastic waste. Taxes are expressed in 2004 euros. The changes in the tax rate are partly due to policy decisions to incentivize sustainable waste treatment,

\footnotetext{
${ }^{7}$ Other policy tools are also used by the Flemish Government such as, landfill bans.

${ }^{8}$ Municipalities can add surcharges, these are equal for every firm in that specific municipality. There exists no panel data on these surcharges. Therefore, we are not able to incorporate these charges in the analysis.

${ }^{9}$ Including cross-sectional invariant variables in a panel analysis does not cause a computational problem.
} 
but are also driven by budgetary reasons. Two years are of special interest because large changes in taxation occurred. In 2007, there was a larger decrease in taxation, 2015 was typed by a large increase.

Next to this tax per ton of industrial plastic waste that is incinerated, a firm also has to pay a waste treatment price - the incineration price. Price levels can be found on the website of the OVAM (https://ovam.be/). This price is a market price, depending on a wide range of factors. The most straightforward being the capacity of incinerators. In 2010 new incineration capacity was put in use and prices dropped as a consequence. In 2015, the thresholds concerning the classification of high- and low calorific value changed. The threshold for high calorific value was raised, resulting in significant price cuts because of the lower supply. This latter example shows that the government still exerts an indirect influence on the price. Another factor of increasing importance is the demand for energy. Incineration facilities are becoming more efficient in energy recovery, and energy supply (Fujii et al., 2019). However, the fraction of energy generated by waste incineration remains small in Flanders (less than $3 \%$ of total energy supply in Flanders).

Figure 1: Incineration tax

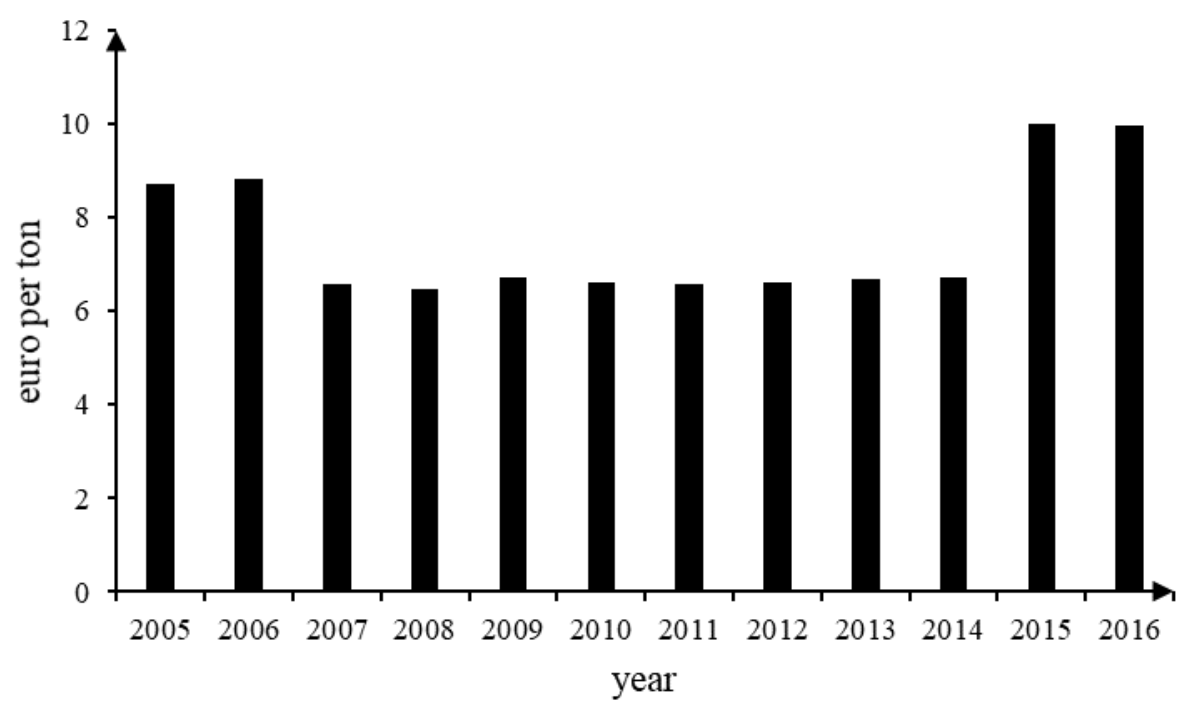

Next to the costs related to incineration, opportunity costs also play a role. Raw material prices - the price of plastics - could therefore influence a firm's behavior. One could think of two possible dynamics: (i) as prices of plastics change, the cost of waste generation changes accordingly, i.e. the wasted material is more expensive. (ii) The changing opportunity cost of the treatment method could result in changing the treatment method. For example, if recycled plastics are cheaper, demand will increase, incentivizing recycling as treatment option. The potential impact of raw material prices is controlled for with a producer price index (PPI) for manufacturers of rubber and plastic products. This index is calculated by Eurostat and the European Central Bank, based on ex-factory-gate prices, including indirect taxes except for VAT, and excluding transport costs. Data on this index can be retrieved form the Eurostat website (https://ec.europa.eu/eurostat/data/database). The index can be used as a good proxy for plastic prices. Using an index instead of actual prices is advantageous to a certain extent, as we do not have to specify the type of plastic with associated prices. Performing an analysis with actual prices of recycled plastics poses some challenges. One has to specify the type, as well as the quality of the plastic, our dataset does not report on either type or quality. Apart from costs incurred by firms, we also incorporate the real GDP per capita. We split up the GDP into the primary and secondary sector's GDP, and the tertiary sector's GDP. The general economic climate might influence waste generation. Next to that, by splitting GDP, we 
measure the waste intensiveness of the different sectors of our economy. Data on GDP can be retrieved form the Eurostat website (https://ec.europa.eu/eurostat/data/database).

\section{Method}

Two types of panel ${ }^{10}$ models exist: static panel models, and dynamic panel models. Dynamic panel models use an autoregressive term - i.e. lagged dependent variable - to detect underlying dynamics. This study considers a dynamic model cf. supra model (equation 5).

There are several reasons why one would choose to estimate a dynamic model. The main reason would be to estimate the influence or autocorrelation of the lagged dependent variable. This estimate can give valuable information if the data has a dynamic nature, i.e. this year's result is partly driven by last year's. We proof that current waste generation is partly determined by the previous waste generation. Intuitively, one could assume that, e.g. waste minimization will only occur after production processes change or certain investments are made. Besides estimating the influence of the lagged dependent variable, a dynamic model helps estimating other parameters. Measuring these underlying dynamics allows a more accurate estimation of the other parameters and their coefficient (Bond, 2002).

Special techniques have been developed to deal with three types of bias occurring in dynamic panel models: dynamic endogeneity, unobserved heterogeneity, and reverse causality (Windmeijer, 2005). In this research we use the Least Squares Dummy Variable Corrected (LSDVC) method for our estimations. This method is related to the Least Square Dummy Variable (LSDV) (this is the standard fixed effects estimator used for panel models), which shows a downward bias when estimating a dynamic model (Bond, 2002). The corrected version (LSDVC) was introduced by Kiviet (1995), in which the bias is approximated and added to the LSDV estimation. The LSDVC uses the consistent ${ }^{11}$ Generalized Method of Moments (GMM) estimators for the bias approximation. In fact, these estimates are plugged in the bias-approximation formulas. The results are then used to correct the biased LSDV ${ }^{12}$. The LSDVC version introduced by Kiviet (1995), was later augmented by Bruno (2005) such that it can also be applied for unbalanced ${ }^{13}$ panel datasets. Next to the augmentation, Bruno (2005) showed that the LSDVC method outperforms the GMM or IV approach in small panels (small N). It is important to note that the LSDVC can only be applied in the presence of strict exogeneity between the independent variables and the error term (Bun \& Carree, 2006).

In order to compute the LSDVC estimation, we need to consider the GMM approach, so that the consistent estimators can be plugged into the bias-approximation formulas. There exist two GMM designs, the original design introduced by Arellano \& Bond (1991) which is also referred to as 'difference GMM', and the augmented 'system GMM' introduced by Arellano \& Bover (1995), Blundell \& Bond (1998). The major difference between the two designs is that the system GMM allows for more internally generated instruments, explained in the next paragraph, which increases the efficiency ${ }^{14}$ of the estimation. However, increasing the number of instruments could overfit the model, weaken the Hansen J-statistic as well as the Sargan statistic. Both tests control for overfitting. Overfitting is the extraction of noise and considering the noise as if it represents an underlying model structure. For that reason, we choose to work

\footnotetext{
${ }^{10}$ Multiple observations of multiple variables at points in time.

${ }^{11}$ A consistent estimator is characterized by a convergence of the estimator to the true value of the parameter when the number of data point grows. The probability of the estimator being equal to the true value of the parameter is asymptotically reaching 1 if the number of data point is growing to infinity.

12 The challenging part of the LSDVC method lies in the bias-approximation formulas. However, we will not elaborate on this matter in this research. Interested readers can find an overview on the literature in Bruno (2005).

${ }^{13}$ Panel data can be balanced, i.e. every company is observed every year, or unbalanced, i.e. not every company is observed every year, new companies can be added to the observations.

${ }^{14}$ An estimator is efficient when the estimation is performed so that the variance is minimized.
} 
with only one instrument for each variable and lag distance. Furthermore, we consciously choose to incorporate only the first lag of the dependent variable (Roodman, 2009).

Instruments are necessary because the lag of the dependent variable will always be correlated with the error term, resulting in inconsistent estimates. Good instruments should not be correlated with the error term, but correlated with the endogenous lagged dependent variable. The GMM design has a great ease of use, as instruments can be generated internally. Two approaches exist for instrument generation: firstdifferencing, and forward orthogonal deviation (FOD). First-differencing is the technique of differencing the current observation with the previous observation. Any constants are neutralized by applying this technique. FOD transforms, rather than subtracts the previous observation, subtracts the average of all available future observations. Typically FOD is preferred in unbalanced panels because it has the virtue of preserving sample size (Roodman, 2009; Ullah, Akhtar, \& Zaefarian, 2018).

Both GMM designs can be estimated with a one- or two-step estimation. When there are more moment conditions than variables ${ }^{15}$, all moments could be given an equal weight, the weighting matrix would in that case be an identity matrix. The result of an estimation with such assumption is obtained after a onestep GMM estimation. However, one could opt to weigh moments according to the sum of squares. The result is an optimal weighting matrix which is obtained after a two-step GMM estimation. In this matrix, moments with a higher variance are given less weight. In our two-step estimations, we consequently specify the Windmeijer (2005) robust standard deviations, to resolve the otherwise downward bias. The post estimation tests computed for our analysis are the Hansen J-statistic, testing for overidentifying restrictions, and the $\mathrm{AR}(2)$ test which measures the validity of the instruments, i.e. checking for the absence of any correlation between the instruments and the error term. Next to these tests, the square root of the error variance (Bruno, 2005) is calculated and denoted by $\sigma$. It speaks for itself that the best fitting approach is represented by the smallest sigma.

Next to the LSDVC and GMM estimations, we also consider the LSDV and Dynamic Ordinary Least Squares (DOLS) estimations as robustness checks. In large samples, the LSDV estimator is known to be downward biased, the DOLS estimator is known to be upward biased (Bond, 2002). Given these biases, we known that the coefficients of the LSDVC estimations should be in between the one's estimated by the LSDV and the DOLS.

\section{Results}

Tables 2 and 3 show the results of the estimations of industrial plastic waste generation in relation to an incineration tax. The analysis consists of two parts: (i) a first part analyzing an unbalanced panel dataset ranging from 2005-2016, (ii) a second part analyzing a balanced panel dataset ranging from 2010-2016. Both parts of the analysis study multivariate dynamic models. All estimations strongly suggest that our data is of a dynamic nature. Present waste generation is partly determined by previous waste generation. All models consider only one time lag of the dependent variable as an independent variable. Considering more lags could result in over-fitting, and as a consequence a spurious estimation.

\subsection{Part one: unbalanced panel dataset 2005-2016}

The first part of the analysis studies LSDVC models as well as GMM models. We find results confirming that the LSDVC can outperform the GMM (Bruno, 2005). We show and discuss the GMM estimations in appendix A.1. These estimations are needed as a consistent estimator for the LSDVC approach. Besides, the GMM estimations allow us to argue why the LSDVC estimations are superior.

Table 2 shows the LSDVC estimations. We find that this year's growth of industrial plastic waste generation is negatively influenced by last year's. However, the impact is limited, a $100 \%$ change in in

\footnotetext{
${ }^{15}$ One could obtain variables with a fraction of the moment conditions. For a correct estimation the GMM uses all available moment conditions.
} 
last year's growth of industrial plastic waste generation has a -1.8 or -1.9 percentage point change in this year's growth of industrial plastic waste generation. The same technique of interpretation holds for all coefficients. Next to the lagged dependent variable, we find that a growth in taxation on incineration has a strong negative effect on the growth of industrial plastic waste generation. In two of the four estimations we include the growth rate of the market price for treatment, which both times is reported to be insignificant. We choose to exclude this variable in the two other estimations, as well as the GMM estimations because this price is a market price and is thus partly determined by the supply of waste on the market. However, this possible endogeneity has to be nuanced. The type of waste, which is researched in this paper, is only a fraction of the market supply. Therefore, we believe that possible endogeneities are unlikely or very limited. In both cases the inclusion exerts an influence on the coefficient for the growth of incineration taxes. It is unclear which coefficient for incineration taxes is more accurate, given the possible issues linked to the market price for the treatment. The negative sign of this coefficient remains robust. A negative effect is found for the growth in PPI. A positive effect on the growth of industrial plastic waste generation is found with the growth in GDP, driven by the primary and secondary sector.

339 The LSDVC estimations are more robust compared to the GMM estimations. The estimated coefficients 340 are in between the LSDV and DOLS estimation coefficients (appendix A.2), and therefore, assumed not 341 to be biased. Moreover, the square roots of the error variance values are lower compared to the ones of 342 the GMM estimations. As mentioned before, the LSDVC uses the consistent GMM estimators for the bias 343 correction. Although we are inclined to build further on the difference GMM (explanation in appendix 344 A.1), we also perform the LSDVC estimation using consistent system GMM estimators. The 345 abbreviations "BB" and "AB" in the table refer to Blundell-Bond (difference) or Arellano-Bond (system).

346

Table 2: Estimation of waste generation - LSDVC

\begin{tabular}{lllll}
\hline & LSDVC-BB & LSDVC-BB & LSDVC-AB & LSDVC-AB \\
\hline & & & & \\
lagged growth waste generation & $-0.018^{* * *}$ & $-0.018^{* * *}$ & $-0.019^{* * *}$ & $-0.019^{* * *}$ \\
& $(0.006)$ & $(0.005)$ & $(0.006)$ & $(0.005)$ \\
growth incineration tax & $-10.085^{* *}$ & $-42.857^{* *}$ & $-10.213^{* *}$ & $-42.833^{* * *}$ \\
& $(4.871)$ & $(16.670)$ & $(4.813)$ & $(16.545)$ \\
growth market price treatment & 42.843 & & 42.656 & \\
& $(27.179)$ & & $(26.985)$ & $-10.387^{* * *}$ \\
growth PPI & $-9.265^{* *}$ & $-10.402^{* * *}$ & $-9.257^{* *}$ & $(3.593)$ \\
growth GDP prim \& sec & $(3.852)$ & $(3.615)$ & $(3.830)$ & 0.275 \\
& $0.342^{* * *}$ & 0.275 & $0.341 * * *$ & $(0.180)$ \\
growth GDP tertiary & $(0.123)$ & $(0.180)$ & $(0.123)$ & -0.647 \\
& -0.595 & -0.648 & -0.594 & $(0.610)$ \\
Observations & $(0.598)$ & $(0.613)$ & $(0.595)$ & 1,154 \\
Number of firms & & & & 252 \\
$\sigma$ & 1,154 & 1,154 & 1,154 & 96.298 \\
\hline
\end{tabular}

Standard errors in parentheses

$* * * \mathrm{p}<0.01, * * \mathrm{p}<0.05, * \mathrm{p}<0.1$

347

348

4.2 Part two: balanced panel dataset 2010-2016 
The second part of the analysis also studies dynamic panel models. The panel dataset which is used in part one is adjusted such that we have a balanced panel dataset, ranging between 2010 and 2016. We choose to work with this shorter panel for two reasons: (i) 'short' to have enough firms in the balanced dataset (65), the longer the balanced dataset, the lower the number of firms. (ii) 'Balanced' because only PRTR firms are included, if a price-sensitive PRTR firm reduced its waste generation to a level under the PRTR threshold, the firm will not be part of the dataset anymore. That means that the relation over time of taxation and waste generation could be wrongly estimated. By taking into account a balanced panel, we can control for this possible selection bias. This second part of the analysis only considers LSDVC models. Judson \& Owen (1999) showed that the LSDVC approach is superior to GMM method for balanced panel datasets.

359 Table 3 shows the results of the LSDVC estimations for the shorter but balanced panel dataset. Results 360 for the lagged dependent variable are larger, persistently negative and still highly significant. The impact 361 is larger, a $100 \%$ change in in last year's growth of industrial plastic waste generation has a -54 to -65 percentage point change in this year's growth of industrial plastic waste generation. When the growth rate of the market price for treatment is not included, we find significant results for the growth rate of the incineration tax, and the growth rate of both fractions of the GDP. When the growth rate of the market price for treatment is included, the growth rate of the incineration tax is found not to be significant. We assume this result is driven by the rather low variability in taxation and a larger variability in the treatment price for these selected years.

368 All results follow are in line with our previous results but seem to be more pronounced compared with the longer, though unbalanced dataset. These more pronounced results are probably driven by the differences of the data during the interval 2010-2016. After performing an LSDV and DOLS estimation for this particular dataset, we find that results of both LSDVC estimations are in between the LSDV and DOLS estimation coefficients and thus robust (appendix A, Table A.3).

Table 3: Estimation of waste generation - LSDVC balanced

\begin{tabular}{|c|c|c|c|c|}
\hline & LSDVC-BB & LSDVC-BB & LSDVC-AB & LSDVC-AB \\
\hline lagged growth waste generation & $\begin{array}{l}-0.550 * * * \\
(0.031)\end{array}$ & $\begin{array}{l}-0.540 * * * \\
(0.036)\end{array}$ & $\begin{array}{l}-0.650 * * * \\
(0.041)\end{array}$ & $\begin{array}{l}-0.642 * * * \\
(0.048)\end{array}$ \\
\hline growth incineration tax & $\begin{array}{l}-12.428 \\
(152.612)\end{array}$ & $\begin{array}{l}-72.309 * * * \\
(16.014)\end{array}$ & $\begin{array}{l}-14.705 \\
(154.587)\end{array}$ & $\begin{array}{l}-66.823 * * * \\
(15.148)\end{array}$ \\
\hline growth market price treatment & $\begin{array}{l}45.381 \\
(110.659)\end{array}$ & & $\begin{array}{l}42.622 \\
(113.480)\end{array}$ & \\
\hline growth PPI & $\begin{array}{l}-2.404 \\
(6.094)\end{array}$ & $\begin{array}{l}-0.838 \\
(5.466)\end{array}$ & $\begin{array}{l}-2.305 \\
(5.917)\end{array}$ & $\begin{array}{l}-0.981 \\
(5.323)\end{array}$ \\
\hline growth GDP prim \& sec & $\begin{array}{l}0.987 \\
(2.539)\end{array}$ & $\begin{array}{l}2.091 * * * \\
(0.302)\end{array}$ & $\begin{array}{l}1.045 \\
(2.581)\end{array}$ & $\begin{array}{l}2.024 * * * \\
(0.314)\end{array}$ \\
\hline growth GDP tertiary & $\begin{array}{l}-1.157 \\
(3.832)\end{array}$ & $\begin{array}{l}-2.815 * * * \\
(0.106)\end{array}$ & $\begin{array}{l}-1.270 \\
(3.944)\end{array}$ & $\begin{array}{l}-2.717 * * * \\
(0.123)\end{array}$ \\
\hline Observations & 401 & 401 & 401 & 401 \\
\hline Number of firms & 69 & 69 & 69 & 69 \\
\hline$\sigma$ & 67.565 & 69.019 & 67.272 & 67.176 \\
\hline
\end{tabular}

Standard errors in parentheses

$* * * \mathrm{p}<0.01, * * \mathrm{p}<0.05, * \mathrm{p}<0.1$ 


\section{Conclusion}

The empirical results indicate that a growth of a tax on industrial plastic waste incineration in Flanders has a significant negative influence on the growth of plastic waste generation by firms. However, more research with larger balanced panel datasets is needed to confirm our results. We find highly significant coefficients for the lagged dependent variable, confirming the dynamic nature of our dataset. Therefore, we choose to work with specially developed methodologies for dynamic panel regressions. We make a distinction between a first part of the analysis, taking into account an unbalanced panel dataset, and a second part taking into account a balanced but shorter panel dataset. First, we perform difference and system GMM estimations. We find a subtle indication that the difference GMM might be preferred over the system GMM. Though, we also find that both GMM approaches are not best suited for the dataset. Therefore, we do consider the LSDVC approach, taking both the difference and system GMMs' consistent estimators into account. We argue that the indication to choose the difference GMM over the system GMM is not pronounced strong enough to ignore the consistent system GMM estimators in the LSDVC approach.

Apart from the tax on incineration, selected estimations take into account the market price for incineration. We do not find significant results for the growth rate of this market price, even if this price is nearly the tenfold of the tax. This result implies that firms are probably less sensitive to market driven prices, compared to taxes. This could indicate that taxes are an efficient policy tool to change behavior. Including the growth rate of the market price for treatment does influence the magnitude of the growth in tax coefficient.

By including the producer price index for manufacturers of rubber and plastic products, we find that a growth in material prices exerts a significant negative influence on the growth of industrial plastic waste generation. We elaborate on the two dynamics which can cause this effect, and argue why only one dynamic - waste minimization - can take place in the current setup of the market. Including two fractions of the growth of GDP per capita: one fraction driven by the primary and secondary sector, another fraction driven by the tertiary sector, shows us interesting results. We find that the fraction driven by the primary and secondary sector exerts a significant positive influence on industrial plastic waste generation. Intuitively, this result makes sense. In the first part of the analysis we do not find significant results driven by the growth of GDP of the tertiary sector. However, the second part reports significant negative results. Overall, similar but smaller results are found by Sasao (2014). Possible causes for these different magnitudes cannot be found in the data itself, we argue that cultural differences, and different policies are probably the driving factor.

Following our results and reasoning above, we advise policymakers to raise taxes prudently. Section 2 makes clear that raising taxes causes different dynamics to take place in the short and long run. This study focusses on the short run, and finds that firms can change their waste generating behavior after taxation. However, the effectiveness of rising taxes will diminish quickly. That is because the marginal cost of reducing waste incineration will become larger than the cost of incineration plus taxation.

Concerning the long run, it is extremely important that the capacity to recycle industrial plastic waste is increased, so that the waste fraction which cannot be reduced anymore can be recycled instead of incinerated. It would be inefficient to tax firms on waste incineration in an environment in which waste reduction efforts are virtually exhausted due to increasing marginal waste reduction costs. Section 2 argues that plastic waste streams will easily find their way to recycling whenever the capacity is in place and the marginal cost of recycling is the lowest. It is the policymaker's task to boost investments in recycling capacity in the short run, and maintain an equilibrium in the long run in which recycling is the preferred option by the market. This equilibrium can be reached by: (i) leaving incineration taxes as is, given that recycling is already preferred, (ii) increasing taxes on incineration such that recycling becomes the preferred option, (iii) subsidizing recycling such that it becomes the preferred option. 
This study has used cross-sectional invariant variables as explanatory variables for the growth of industrial plastic waste. A future research idea would include cross-sectional variant explanatory variables. It would be interesting to research if certain types of firms, e.g. more profitable firms, provide statistically significant different results. Another interesting research idea would be to study the relation between actual prices of recycled material, not an index, and the treatment method chosen by the industry.

\section{Appendix A}

\section{A.1}

Table A.1: Estimation of waste generation - GMM

\begin{tabular}{lllll}
\hline & D-GGM-1 & D-GMM-2 & S-GMM-1 & S-GMM-2 \\
\hline & & & & \\
lagged growth waste generation & $-0.040^{* * *}$ & $-0.038^{* * *}$ & $-0.035^{* * *}$ & $-0.035^{* * *}$ \\
& $(0.006)$ & $(0.006)$ & $(0.007)$ & $(0.007)$ \\
growth incineration tax & $-526.646^{* * *}$ & $-521.524^{*}$ & $-685.760^{* * *}$ & $-702.105^{* * *}$ \\
growth PPI & $(181.932)$ & $(287.513)$ & $(114.341)$ & $(196.501)$ \\
& 8.549 & 18.578 & 12.950 & 28.659 \\
growth GDP prim \& sec & $(67.986)$ & $(100.214)$ & $(64.492)$ & $(102.018)$ \\
& 4.002 & 6.061 & $5.830^{*}$ & $7.681^{*}$ \\
growth GDP tertiary & $(2.971)$ & $(5.892)$ & $(3.124)$ & $(4.558)$ \\
& $17.944^{*}$ & 14.784 & $16.732^{*}$ & 14.947 \\
Constant & $(10.797)$ & $(12.944)$ & $(9.389)$ & $(13.415)$ \\
& & & -92.118 & -78.021 \\
Observations & & & $(61.120)$ & $(64.845)$ \\
Number of firms & & & 1,154 & 1,154 \\
AR(2) pr $>\mathrm{z}$ & 902 & 902 & 252 & 252 \\
Sargan test pr $>$ chi $^{2}$ & 203 & 203 & 0.369 & 0.403 \\
Hansen test pr $>$ chi $^{2}$ & 0.520 & 0.533 & 0.986 & 0.986 \\
$\sigma$ & 0.628 & 0.964 & 0.827 & 0.827 \\
\hline
\end{tabular}

Note that the constant term is differenced out when estimating with the difference GMM. Robust standard errors in parentheses $* * * \mathrm{p}<0.01, * * \mathrm{p}<0.05, * \mathrm{p}<0.1$

Table A.1 reports the GMM estimations. D-GMM-1 and D-GMM-2 respectively refer to the one-step and two-step difference (Arellano-Bond) GMM. S-GMM-1 and S-GMM-2 respectively refer to the one-step and two-step system (Blundell-Bond) GMM. All estimations report highly significant small negative coefficients for the lagged depended variable. This is a recurring result in the entire analysis and provides proof for the dynamic nature of our dataset. This result also implies that industrial plastic waste generation probably follows a mean-reverting process. All four GMM models find significant negative coefficients for the growth rate of the incineration taxation, confirming our intuitive expectations. However, let us focus on the robustness of the GMM estimations. Both the Sargan test and Hansen test are used to check for over-identifying restrictions, with the null hypothesis of not over-identified restrictions. Following both tests (Sargan and Hansen), we are not yet inclined to choose one GMM design over the other. Both tests clearly do not reject the null hypothesis for all GMM estimations. The 
442

443

444

445

446

447

448

449

450

451

452

453

454

455

456

statistic which might create a preference for the difference GMM is the square root of the error variance denoted with $\sigma$ a lower value is preferred over a high value. The square root of the error variance can be considered as a unit of measure for robustness (Bruno, 2005). Another robustness measure used for e.g. GMM estimations are the LSDV and DOLS estimation. According to Bond (2002), the LSDV estimation shows a downward bias and the DOLS estimation shows an upward bias. Hence, coefficients should be LSDV < GMM < DOLS. Table A. 2 shows the LSDV and DOLS estimations. Considering the LSDV < GMM < DOLS rule, we conclude that the GMM estimations are not optimal for our dataset, e.g. -0.028 $(\mathrm{LSDV})>-0.040$ (D-GMM-1) $<0.000$ (DOLS), and that we should further concentrate on the LSDVC approach. This approach, as mentioned before, uses the consistent GMM estimators. We are inclined to suggest the use of the consistent difference GMM estimators, over the consistent system GMM estimators. However, this suggestion is only based on the square root of the error variance, hence, we will report on both.

\section{A.2}

Table A.2: Estimation of waste generation - LSDV \& DOLS

\begin{tabular}{lll}
\hline & LSDV & DOLS \\
\hline & & \\
lagged growth waste generation & $-0.028^{* * *}$ & 0.000 \\
& $(0.008)$ & $(0.008)$ \\
growth incineration tax & $-42.089^{* *}$ & $-46.887^{* *}$ \\
growth PPI & $(19.014)$ & $(21.013)$ \\
& $-10.217^{* * *}$ & $-10.138^{* * *}$ \\
growth GDP prim \& sec & $(2.633)$ & $(2.816)$ \\
& $0.267 *$ & $0.350^{* *}$ \\
growth GDP tertiary & $(0.147)$ & $(0.159)$ \\
& -0.621 & $-0.831^{* *}$ \\
Constant & $(0.390)$ & $(0.415)$ \\
& $28.791 * * *$ & $30.975^{* * *}$ \\
Observations & $(6.753)$ & $(7.340)$ \\
Number of firms & 1,154 & 1,154 \\
$\mathrm{R}^{2}$ & 252 & \\
\hline Standard errors in parentheses & 0.032 & 0.012 \\
$* * * \mathrm{p}<0.01, * * \mathrm{p}<0.05, * \mathrm{p}<0.1$ & &
\end{tabular}

Table A.3: Estimation of waste generation - LSDV \& DOLS balanced

\begin{tabular}{lllll}
\hline & LSDV & LSDV & DOLS & DOLS \\
\hline \multirow{2}{*}{ lagged growth waste generation } & $-0.716^{* *}$ & $-0.709^{* *}$ & -0.102 & -0.100 \\
& $(0.358)$ & $(0.356)$ & $(0.325)$ & $(0.324)$ \\
growth incineration tax & -9.274 & $-67.555^{* * *}$ & -48.392 & $-68.268^{* * *}$
\end{tabular}




\begin{tabular}{lllll} 
& $(271.512)$ & $(25.067)$ & $(273.174)$ & $(25.232)$ \\
growth market price treatment & 46.999 & & 16.029 & \\
& $(218.016)$ & & $(219.350)$ & \\
growth PPI & -2.419 & -0.973 & -1.312 & -0.819 \\
& $(7.588)$ & $(3.543)$ & $(7.614)$ & $(3.513)$ \\
growth GDP prim \& sec & 0.938 & $2.021^{* * *}$ & 1.727 & $2.097 * * *$ \\
& $(5.068)$ & $(0.654)$ & $(5.098)$ & $(0.657)$ \\
growth GDP tertiary & -1.110 & $-2.704^{* * *}$ & -2.278 & $-2.821^{* * *}$ \\
& $(7.456)$ & $(0.972)$ & $(7.501)$ & $(0.978)$ \\
Constant & 24.986 & $45.885^{* * *}$ & 38.879 & $46.006^{* * *}$ \\
& $(97.546)$ & $(10.804)$ & $(98.142)$ & $(10.878)$ \\
& & & & \\
Observations & 401 & 401 & 401 & 401 \\
Number of firms & 69 & 69 & & \\
$\mathrm{R}^{2}$ & 0.059 & 0.059 & 0.039 & 0.039 \\
\hline Standard errors in parentheses & & & & \\
$* * * \mathrm{p}<0.01, * * \mathrm{p}<0.05, * \mathrm{p}<0.1$ & & & &
\end{tabular}

460 Nomenclature

$\begin{array}{ll}\text { 3R } & \text { Reduce - Reuse - Recycle } \\ \text { AR } & \text { Autoregressive } \\ \text { CE } & \text { Circular Economy } \\ \text { DOLS } & \text { Dynamic Ordinary Least Squares } \\ \text { EAP } & \text { Environmental Action Programme } \\ \text { EC } & \text { European Commission } \\ \text { EU } & \text { European Union } \\ \text { FOD } & \text { Forward Orthogonal Deviation } \\ \text { GDP } & \text { Gross Domestic Product } \\ \text { GMM } & \text { Generalized Method of Moments } \\ \text { LSDV } & \text { Least Squares Dummy Variable } \\ \text { LSDVC } & \text { Least Squares Dummy Variable Corrected } \\ \text { MC } & \text { Marginal Cost } \\ \text { MS } & \text { Member States } \\ \text { OVAM } & \text { Public Flemish Waste Agency } \\ \text { PPI } & \text { Producer Price Index } \\ \text { PRTR } & \text { Pollutant Release and Transfer Register } \\ \text { VAT } & \text { Value Added Tax }\end{array}$

462 References

463 Allwood, J. M. (2014). Squaring the Circular Economy. In Handbook of Recycling (pp. 445-477).

$464 \quad$ Elsevier. https://doi.org/10.1016/B978-0-12-396459-5.00030-1

465 Bartelings, H., Van Beukering, P., Kuik, O., Linderhof, V., Oosterhuis, F., Brander, L., \& Wagtendonk, A. (2005). Effectiveness of landfill taxation. The Hague. Retrieved from http://www.ivm.vu.nl/en/Images/Effective_landfill_R05-05_tcm53-102678_tcm234-103947.pdf

468 Bond, S. (2002). Dynamic panel data models: a guide to micro data methods and practice. Portuguese 
Economic Journal, 1, 141-162. Retrieved from https://link.springer.com/content/pdf/10.1007\%2Fs10258-002-0009-9.pdf

Brooks, A. L., Wang, S., \& Jambeck, J. R. (2018). The Chinese import ban and its impact on global plastic waste trade. Science Advances, 4(6), 7. Retrieved from http://advances.sciencemag.org/

Bruno, G. S. F. (2005). Estimation and inference in dynamic unbalanced panel data models with a small number of individuals. The Stata Journal, 5(4), 473-500.

Bun, M. J. G., \& Carree, M. A. (2006). Bias-corrected estimation in dynamic panel data models with heteroscedasticity. Economics Letters, 92(2), 220-227. https://doi.org/10.1016/j.econlet.2006.02.008

Confino, J. (2015, February 3). Future of Europe's circular economy mired in controversy. The Guardian. Retrieved from https://www.theguardian.com/sustainable-business/2015/feb/03/architect-europecircular-economy-strategy-lambasts-successors

De Jaeger, S., \& Eyckmans, J. (2015). From pay-per-bag to pay-per-kg: The case of Flanders revisited. Waste Management \& Research, 33(12), 1103-1111. Retrieved from https://pdfs.semanticscholar.org/81a9/e82e93ed5750631f0562a60da40edc71a221.pdf

EC. A General Union Environment Action Programme to 2020 (2013). Retrieved from http://eurlex.europa.eu/legal-content/EN/TXT/PDF/?uri=CELEX:32013D1386\&from=EN

EC. (2015). Closing the loop - An EU action plan for the Circular Economy. COM. Retrieved from https://eur-lex.europa.eu/resource.html?uri=cellar:8a8ef5e8-99a0-11e5-b3b701aa75ed71a1.0012.02/DOC_1\&format=PDF

EC. (2018a). A European Strategy for Plastics in a Circular Economy. Brussels. Retrieved from https://eur-lex.europa.eu/resource.html?uri=cellar:2df5d1d2-fac7-11e7-b8f501aa75ed71a1.0001.02/DOC_1\&format=PDF

EC. (2018b). Single-use plastics. Retrieved from https://ec.europa.eu/commission/news/single-useplastics-2018-may-28_en

EC. (2018c). Waste - Environment - European Commission. Retrieved 25 July 2018, from http://ec.europa.eu/environment/waste/index.htm

Fujii, M., Dou, Y., Sun, L., Ohnishi, S., Maki, S., Dong, H., ... Chandran, R. (2019). Contribution to a low-carbon society from improving exergy of waste-to-energy system by upgrading utilization of waste. Resources, Conservation and Recycling, 149, 586-594. https://doi.org/10.1016/j.resconrec.2019.06.038

Fullerton, D., \& Kinnaman, T. C. (1996). Household Responses to Pricing Garbage by the Bag. The American Economic Review, 86(4), 971-984. Retrieved from https://www.jstor.org/stable/pdf/2118314.pdf?refreqid=excelsior\%3Ac07f2ec30a8dd1f146e2de2d49 $609 \mathrm{cdb}$

Gillabel, J., D’Haese, N., Dierckx, P., Vanassche, S., \& Vanderreydt, I. (2016). Stimuleren van het gebruik van gerecycleerde (en secundaire) granulaten in hoogwaardige toepassingen. Retrieved from https://www.ovam.be/sites/default/files/atoms/files/Summa KT opdracht Stimuleren van het gebruik van gerecycleerde granulaten in hoogwaardige toepassingen.pdf

Hart, S. L. (1997). Beyond Greening: Strategies for a Sustainable World. Harvard Business Review, 75, 66-76. https://doi.org/10.1016/j.eiar.2014.04.001

Hopewell, J., Dvorak, R., \& Kosior, E. (2009). Plastics recycling: challenges and opportunities. Philosophical Transactions of the Royal Society B: Biological Sciences, 364(1526), 2115-2126. https://doi.org/10.1098/rstb.2008.0311

Kirchherr, J., Reike, D., \& Hekkert, M. (2017). Conceptualizing the circular economy: An analysis of 114 definitions. Resources, Conservation and Recycling, 127, 221-232. https://doi.org/10.1016/j.resconrec.2017.09.005

Martin, A., \& Scott, I. (2003). The Effectiveness of the UK Landfill Tax. Journal of Environmental Planning and Management, 46(5), 673-689. https://doi.org/10.1080/0964056032000138436

Mazzanti, M., Montini, A., \& Nicolli, F. (2012). Waste dynamics in economic and policy transitions: decoupling, convergence and spatial effects. Journal of Environmental Planning and Management, 55(5), 563-581. https://doi.org/10.1080/09640568.2011.616582 
OECD. (2018). Improving Plastics Management: Trends, policy responses, and the role of international co-operation and trade (OECD Environment Policy Paper No. 12). https://doi.org/10.1126/sciadv.1700782

OVAM. (s.a.). Afval \& materialen - OVAM. Retrieved 17 August 2019, from https://ovam.be/overzichtafval-en-materialen

Porter, M. E., \& van der Linde, C. (1995). Toward a New Conception of the EnvironmentCompetitiveness Relationship. Journal of Economic Perspectives, 9(4), 97-118. https://doi.org/10.1257/jep.9.4.97

Potočnik, J. (2014). Speaking points by Environment Commissioner Janez Potočnik on Circular Economy.

Qu, S., Guo, Y., Ma, Z., Chen, W.-Q., Liu, J., Liu, G., .. Xu, M. (2019). Implications of China's foreign waste ban on the global circular economy. Resources, Conservation and Recycling, 144, 252-255. https://doi.org/10.1016/j.resconrec.2019.01.004

Relis, P. (2017). Recycling: An answer waiting for a solution. Forum for Applied Research and Public Policy, 7(1), 52-55.

Sahlin, J., Ekvall, T., Bisaillon, M., \& Sundberg, J. (2007). Introduction of a waste incineration tax: Effects on the Swedish waste flows. Resources, Conservation and Recycling, 51(4), 827-846. https://doi.org/10.1016/J.RESCONREC.2007.01.002

Sasao, T. (2014). Does industrial waste taxation contribute to reduction of landfilled waste? Dynamic panel analysis considering industrial waste category in Japan. Waste Management, 34(11), 22392250. https://doi.org/10.1016/j.wasman.2014.07.014 